\title{
AVALIAÇÃO COMPARATIVA ENTRE METODOLOGIAS DE IDENTIFICAÇÃO DE SITUAÇÕES DE CONFORTO TÉRMICO HUMANO APLICADO AO CONTEXTO TROPICAL, PRESIDENTE PRUDENTE/BRASIL
}

\author{
FANTE, Karime Pechutti - karimefante@hotmail.com \\ Universidade Estadual Paulista/UNESP Presidente Prudente-SP \\ DUBREUIL, Vincent - vincent.dubreuil@univ-rennes2.fr \\ Université Rennes 2 - LETG-Rennes-COSTEL \\ SANT'ANNA NETO, João Lima - joaolima@fct.unesp.br \\ Universidade Estadual Paulista/ UNESP Presidente Prudente-SP
}

\begin{abstract}
RESUMO: O presente artigo reúne uma avaliação comparativa de 6 diferentes metodologias (índices, diagrama e questionário de predileção) para identificação de situações de conforto térmico aplicado a cidade Presidente Prudente/Brasil. A partir da análise dos índices de temperatura e umidade (THI), índice de temperatura efetiva com vento (TEv), índice de temperatura efetiva (TE), índice de temperatura equivalente percebida (TEP), diagrama de conforto térmico, e da análise de predileção térmica dos residentes em Presidente Prudente foi contabilizado o número de dias com situações confortáveis e desconfortáveis nos períodos das $9 \mathrm{~h}, 15 \mathrm{~h}$ e $21 \mathrm{~h}$, entre os anos de 2005 a 2016, além de discutir as vantagens e desvantagens de utilização para cada técnica. De modo geral os índices tiveram um desenvolvimento parecido na avaliação de situações confortáveis no período da tarde e noite, contudo demonstraram pouco consenso especialmente no período da manhã, horário em que as temperaturas são mais amenas em Presidente Prudente a umidade está relativamente alta. O questionário de predileção térmica e o diagrama de conforto térmico apresentaram os maiores valores percentuais de conforto térmico e chegaram a atingir limiares superiores a $70 \%$ nos três horários analisados (questionário de predileção). Também constatou alguns problemas metodológicos na identificação de extremos de desconforto: o índice de temperatura efetiva com vento apresentou uma tendência a maximizar o resfriamento pelo vento gerando resultados "frios" e o diagrama de conforto, de acordo com a disposição das variáveis, tende a mascarar as condições térmicas e superestima o resultado para a classificação de "Muito úmido".
\end{abstract}

Palavras- chaves: conforto térmico, índices de conforto, diagrama bioclimático, questionário, Presidente Prudente.

COMPARATIVE EVALUATION BETWEEN METHODOLOGIES FOR IDENTIFICATION OF HUMAN THERMAL COMFORT SITUATIONS APPLIED TO TROPICAL CONTEXT, PRESIDENTE PRUDENTE/BRAZIL.

ABSTRACT: This paper compiles a comparative evaluation between 6 different methodologies (indexes, diagram and questionnaire of preference) to identify situations of thermal comfort applied to Presidente Prudente - Brazil. After to analyse the Temperature and humidity indexes (THI), Effective temperature index with wind (TEv), Effective temperature index (TE), Perceived equivalent temperature index (TEP), Thermal comfort diagram, and analysis of the Thermal preferences questionnaire of the residents of Presidente Prudente were accounted the number of days with comfortable and uncomfortable situations in the periods of $9 \mathrm{~h}, 15 \mathrm{~h}$ and $21 \mathrm{~h}$, between 2005 at 2016, also was discuss the advantages and disadvantages for the use of each technique. In general, the indices had a similar development in the evaluation of comfortable situations in the afternoon and evening, although they showed little consensus especially in the morning, when temperatures are milder and the humidity is relatively high in Presidente Prudente. The Thermal preference questionnaire and the Thermal comfort diagram showed the highest percentage of comfort and reached thresholds above $70 \%$ in the three schedules 
analyzed (predilection questionnaire). It also found some methodological problems in the identification of extremes of discomfort: the Effective temperature index with wind presented a tendency to maximize the cooling by the wind generating results considered "cold" and the Comfort diagram, according to the arrangement of the variables, ends up mask the thermal conditions and overestimate the result for the classification of "very humid".

Keywords: thermal comfort, comfort indexes, bioclimatic diagram, questionnaire, Presidente Prudente.

ANALYSE COMPARATIVE DE MÉTHODOLOGIES D'IDENTIFICATION DES SITUATIONS DE CONFORT THERMIQUE HUMAIN APPLIQUÉES AU CONTEXTE TROPICAL, PRÉSIDENTE PRUDENTE / BRÉSIL.

RÉSUMÉ: Cet article présente une évaluation comparative de six méthodes différentes (indice, diagramme et questionnaire de prédilection) pour l'identification des conditions de confort thermique appliquées à Presidente Prudente / Brésil. Nous avons analysé les indices de la Température et d'humidité (THI), la Température effective avec le vent (TEv), la Température effective (TE), la Température perçue équivalente (TPE), le diagramme de confort thermique et l'analyse de préférence thermique des résidents à Presidente Prudente. Le nombre de jours confortables et inconfortables ont été comptabilisés pour $9 \mathrm{~h}, 15 \mathrm{~h}$ et $21 \mathrm{~h}$, entre les années 2005 à 2016 : les avantages et les inconvénients pour l'utilisation de chaque technique sont présentés. En général, les indices présentent des résultats similaires pour les situations confortables l'après-midi et le soir contrairement au matin, période où les températures sont plus basses et I'humidité relative élevée à Presidente Prudente. Le Questionnaire de préférence thermique et le Diagramme de confort thermique ont montré les pourcentages les plus élevés de confort thermique en atteignant des seuils supérieurs à $70 \%$ pour les trois horaires analysés (Questionnaire de prédilection). L'étude montre également quelques problèmes méthodologiques pour l'identification des extrêmes d'inconfort: I'indice de température effective avec le vent a montré une tendance à maximiser les résultats de refroidissement par le vent, générant ainsi beaucoup de résultats considérés comme « froid »; le Diagramme de confort, du fait de la disposition des variables, masque les conditions thermiques et surestime le résultat de la classe de "très humide".

Mots Clés: confort thermique, indices de confort, diagramme bioclimatique, questionnaire, Presidente Prudente.

\section{INTRODUÇÃO}

O homem, ser vivo homeotérmico, depende de condições climáticas apropriadas para o funcionamento regular do seu organismo. Fatores como a temperatura, umidade, vento e demais elementos do clima tem influência direta no bom desenvolvimento fisiológico humano. Quando esta situação adequada não ocorre o organismo humano tem que se esforçar para manter as condições básicas para o seu funcionamento o que pode gerar certo desgaste e, consequentemente, problemas de saúde e enfermidades (BESANCENOT, 2001).

Contudo, definir o que é confortável ou desconfortável do ponto de vista térmico requer a análise de diversos fatores fisiológicos, individuais, ambientais e subjetivos que juntos conjugam a sensação de bem ou mal estar térmico individual. Nem sempre os mesmos limiares e limites térmicos são agradáveis a todos os grupos e, portanto, há uma série de definições sobre este conceito.

De modo geral o conforto térmico humano pode ser definido como el conjunto de condiciones en las que los mecanismos de autorregulación son mínimos o como la zona delimitada por unos umbrales térmicos en la que el 
mayor número de personas manifiesten sertirse bien (GARCÍA, 1996, p. 199). Quando as condições de neutralidade são alteradas o organismo humano responde rapidamente a partir de processos internos como a vasoconstrição, vasodilatação, termogênese e sudação visando reestabelecer o equilíbrio em torno de $37^{\circ} \mathrm{C}$ (BESANCENOT, 2001; FROTA E SCHIFFER, 2001; CARVALHO, 2006; GARCÍA, 1996).

Diversas variáveis podem amenizar e agravar a relação entre homemmeio e a percepção do conforto térmico. De acordo com Carvalho (2006, p.54) estas variáveis podem ser divididas em:

Humanas (individuais e fisiológicos): cujo estão intrínsecos processos como o metabolismo (CARVALHO, 2006, p.55), as atividades desenvolvidas, o sexo (GOBO et. al., 2017), formas do corpo, massa corporal (BURSE, 1979; LEBLANC et. al., 1978) e gordura hábitos alimentares (KRUNGER et. al. 2012, p.21), idade (COLLINS, EXTON-SMITH e DORÉ, 1981), estado de saúde (JENDRITZKY, 1993), vestuário (FROTA e SCHIFFER, 2001, p.23) e aclimatização dos indivíduos;

As variáveis ambientais são aquelas relacionadas aos elementos do clima: temperatura, vento, umidade, radiação (BESANCENOT, 2001, p.09; MONTEIRO, 2013, p.155)

E as variáveis subjetivas associam-se as experiências passadas, expectativas, tempo de exposição, necessidades ambientais, estímulos ambientais, controle percebido, preferências individuais e culturais (NIKOLOPOULOU e STEEMERS, 2003, p.99).

Para as pesquisas de conforto térmico normalmente são utilizadas e relacionadas algumas destas variáveis. Existe na bibliografia nacional e internacional uma numerosa quantidade de metodologias e equações que podem ajudar nesta avaliação, contudo, cada técnica considera diferentes variáveis e elementos a partir da intencionalidade da pesquisa.

Definir uma melhor técnica não é tarefa fácil e talvez, neste momento, ainda não exista uma metodologia aplicável a todos os contextos climáticos e sujeitos de pesquisa. Isto dependerá, principalmente, da intencionalidade e objetivo de cada pesquisa.

Para a cidade de Presidente Prudente, por exemplo, área de estudo desta pesquisa, as metodologias para análise de conforto térmico são aquelas indicadas para o clima tropical. Presidente Prudente localiza-se no interior do estado de São Paulo há $560 \mathrm{~km}$, aproximadamente, distante da capital, São Paulo. É caracterizada como uma cidade de porte médio e no último censo, 2010, contou com a população de 207.610 habitantes (Figura 1). 


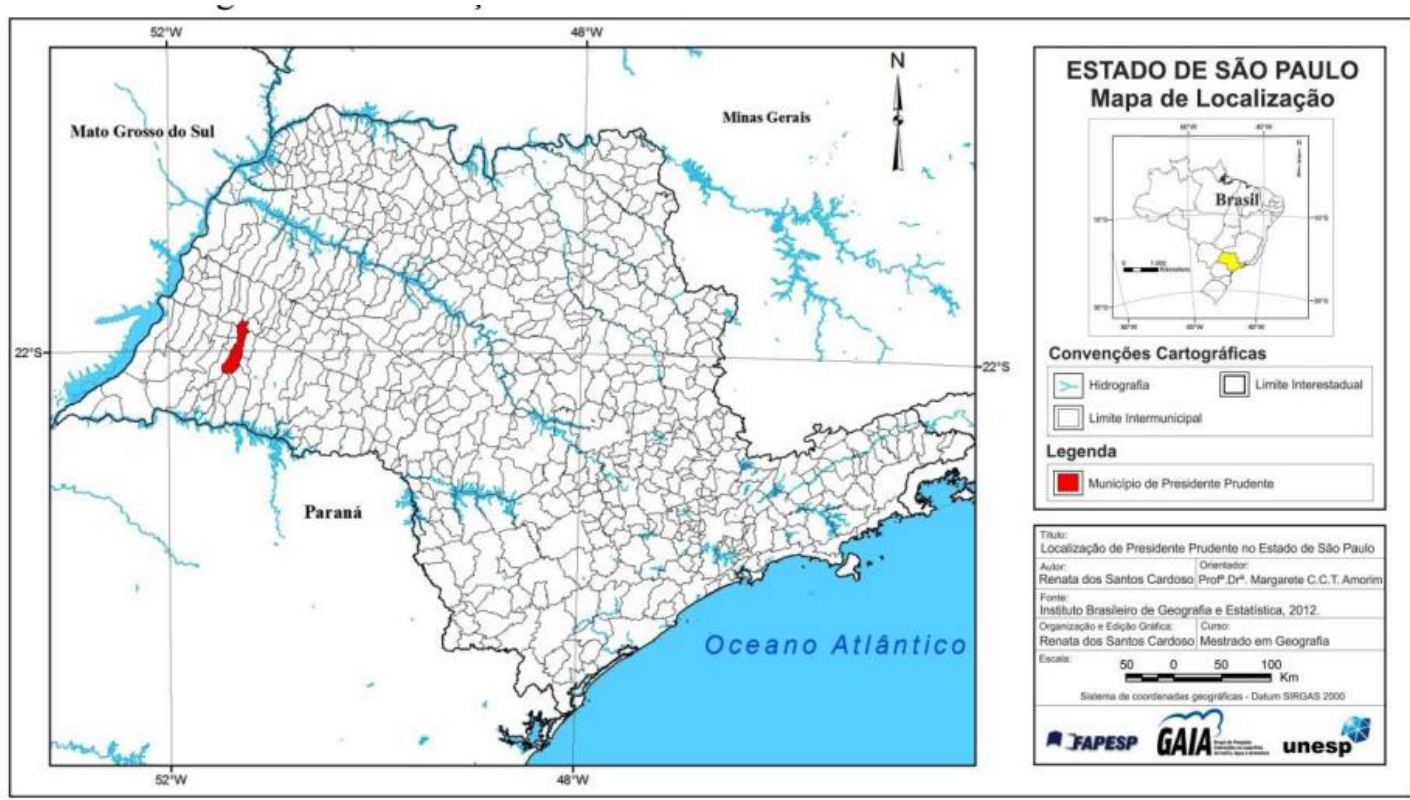

Figura 1 - Localização de Presidente Prudente no Estado de São Paulo.Fonte: Cardoso (2015, p. 25).

De acordo com Sant'Anna Neto e Tommaselli (2009, p.11) este município:

\begin{abstract}
situa-se numa área de transição entre os climas zonais controlados pelos sistemas tropicais, que Ihe confere elevadas temperaturas de primavera e verão, e pelos sistemas extratropicais (massas polares) que ocasionam episódios de invasão das frentes frias e do ar polar no outono e inverno, provocando baixas temperaturas.
\end{abstract}

Dubreuil et. al. (2017, p. 10 e 15), com base na teoria de Köppen e a partir da análise das frequências dos tipos de tempo realizada para todo o Brasil, caracterizou o clima deste município como Aw, clima tropical com chuva de verão. Segundo os autores, entre os anos de 1961 a 2015, mais de $80 \%$ dos anos tiveram esse padrão. De acordo com Fante (2014, p.74) a média das temperaturas máximas e mínimas neste local é de $29,1^{\circ} \mathrm{C}$ e $18^{\circ} \mathrm{C}$, respectivamente, sendo que as maiores temperaturas anuais no decorrer da série analisada, 1961 a 2011, ocorreram principalmente após a década de 2000 (Figuras 02 e 03). 

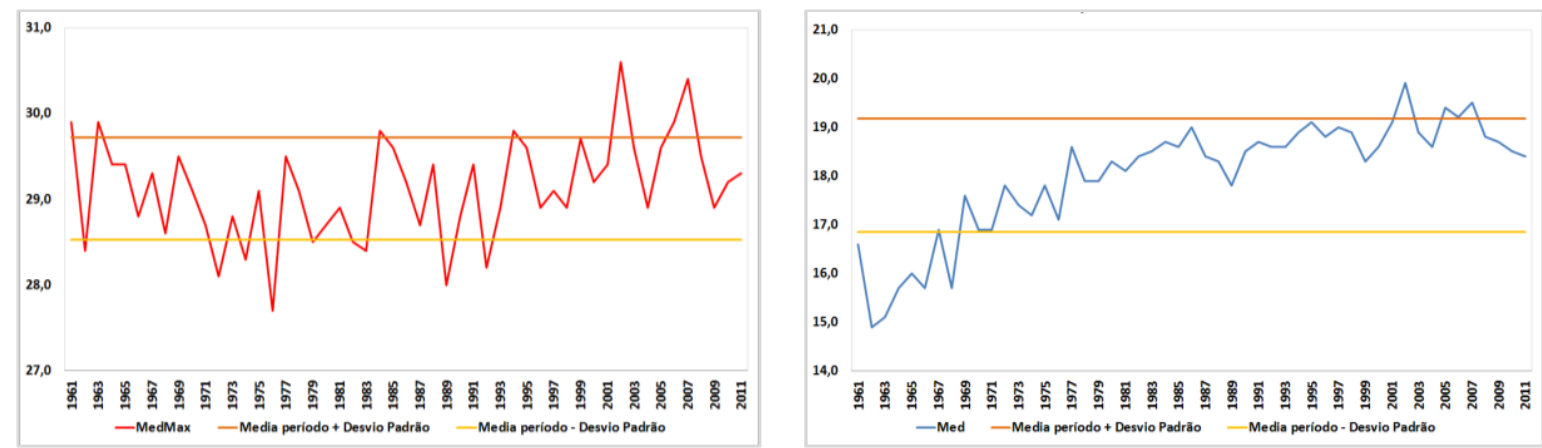

Figuras 02 e 03 - Médias anuais das temperaturas máximas e mínimas em Presidente Prudente e desvio padrão positivo e negativo do período (1961-2011).

Fonte: Fante (2014, p. 115 e 116).

Embasados nesta discussão esta pesquisa teve o objetivo de testar e comparar o desempenho de diferentes metodologias aplicáveis a análise do conforto e desconforto térmico. Buscou-se avaliar os limites e (des)vantagens para cada técnica, além de contabilizar e comparar o número de ocorrências confortáveis nos períodos das 9h, 15h e $21 \mathrm{~h}$ (manhã, tarde e noite) na cidade de Presidente Prudente, São Paulo/Brasil, nos últimos 11 anos (2005 a 2016).

\section{MATERIAL E MÉTODOS.}

Para esta pesquisa foram selecionadas 3 metodologias diferentes para análise do conforto térmico humano: índices, diagrama e questionário aplicado com a população residente na cidade estudada.

De acordo com Bogo et. al. (1994, p.11) os índices de conforto térmico tem a finalidade de quantificar o comportamento humano ante o ambiente térmico, de acordo com o modelo teórico em estudo, são definidos índices que expressam esta relação de causa e efeito, com a utilização de valores numéricos representativos do fenômeno.

Existe uma grande variedade de índices que podem ser aplicados para a análise do conforto térmico. Para a eleição dos índices que compõem este artigo foram considerados os seguintes critérios:

1) Eleição de índices apropriados a realidade tropical;

2) Exclusão dos índices fisiológicos em que não havia condições e conhecimentos suficientes para analisá-los com maior detalhamento, como exemplo, os índices que consideram dados de taxas de suor, energia metabólica, intercâmbio de calor convectivo, evaporativo, condutivo, entre outros;

3) Escolha por índices que consideram na sua equação os dados climatológicos disponíveis pelo Instituto Nacional de Meteorologia. Não foi possível utilizar, por exemplo, índices que consideram valores de radiação, insolação e/ou duração solar; 
4) Preferência por índices em que haviam na bibliografia consultada classificações e limiares de conforto e desconforto térmico;

5) Opção por índices que utilizam diferentes variáveis climatológicas na sua formulação: temperatura e umidade; temperatura e velocidade do vento; temperatura, velocidade do vento e umidade, por exemplo.

6) Escolha por índices aplicáveis tanto para situações de desconforto térmico associados ao frio quanto ao calor (alguns índices são específicos para análises de calor ou de frio).

7) Opção por índices aplicados a ambientes externos.

Os diagramas são figuras utilizadas para análise do conforto térmico. Os dados atmosféricos são plotados nesta figura a partir de um eixo de coordenadas ( $x$ e y) e o local da abscissa refere-se a situação momentânea definidas a partir de cada diagrama. De forma simples e objetiva esta metodologia apresenta situações e limiares relacionados ao conforto térmico a partir da variação dos elementos atmosféricos (temperatura, umidade, por exemplo).

Para esta pesquisa foi considerado o diagrama bioclimático oferecido pelo Instituto Nacional de Meteorologia. O intuito, além de ser uma metodologia diferente dos tradicionais índices, é o de trazer a discussão um dos produtos desenvolvidos a nível nacional.

Na maioria das pesquisas em conforto térmico a população é consultada e estudada a partir de questionários dirigidos. Normalmente as pesquisas são feitas dentro de ambientes controlados e com um grupo de pessoas também selecionadas. A vantagem desta metodologia é que a população, foco principal dos estudos em conforto térmico, faz parte do processo de pesquisa e são ouvidas. Suas preferências, sensações e níveis de satisfação e insatisfações são considerados. Este é um dos princípios fundamentais para posterior elaboração de índices e diagramas.

Para a presente pesquisa a utilização dos questionários, ainda que de maneira incipiente e simples, foi uma tentativa de aproximação desta pesquisa com a população residente em Presidente Prudente, conforme trataremos com mais detalhes a seguir.

Com base nesses critérios foram selecionadas as seguintes técnicas:

- $\quad$ Índice de temperatura e umidade (THI) elaborada por Thom (1959);

- Índice de temperatura efetiva com vento (TEv) desenvolvida por Missenard (1937);

- Índice de temperatura efetiva (TE) também elaborada por Missenard (1948);

- Índice de temperatura equivalente percebida (TEP) proposto pelo arquiteto brasileiro Monteiro (2008) em sua tese de doutorado;

Diagrama bioclimático: diagrama de conforto térmico (INMET);

- Resultados do questionário aplicado a população de Presidente Prudente referentes a predileção térmica.

Estas técnicas foram aplicadas para o período diário de 01/01/2005 a 31/12/2016, nos horários representativos da manhã, 9h; tarde, $15 \mathrm{~h}$; e, noite, 21h. Os dados climáticos utilizados: temperatura, umidade e velocidade do 
vento, foram obtidas na estação meteorológica de Presidente Prudente mantida pelo Instituto Nacional Meteorológico (INMET).

Os índices, diagrama e resultado do questionário são descritos por:

\section{- Índice de temperatura e umidade (THI) - Thom (1959)}

O índice de temperatura e umidade (THI) - Thom (1959) é um dos mais utilizados e citados na bibliografia nacional e internacional. Contudo parece haver uma confusão entre os pesquisadores que utilizam esse índice. Foram encontradas diversas equações diferentes intituladas como Índice de temperatura e umidade (THI). Por se tratar de uma referência antiga poucos têm acesso ao original e diante desse fato optou-se pela equação mais utilizada pela bibliografia consultada:

$$
\mathrm{THI}=\mathrm{Ts}-(0,55-0,0055 \mathrm{UR})(\mathrm{Ts}-14,5)
$$

THI = é o índice de temperatura e umidade $\left({ }^{\circ} \mathrm{C}\right)$

Ts $=$ temperatura do ar do bulbo seco $\left({ }^{\circ} \mathrm{C}\right)$ $\mathrm{UR}=$ umidade relativa (\%)

Fonte: Funari (2006); Pereira, Aleixo e Silva Neto (2016, p.921); Besancenot (2001, p.45) e Boubaker (2010, p. 60).

Para esta equação foram admitidas as classificações de conforto utilizadas pelos autores brasileiros: Funari (2006) e Pereira, Aleixo e Silva Neto (2016, p.921):

Tabela 01 - Classes de desconforto termo-higrométricos para o índice de Thom (1959).

\begin{tabular}{|c|c|}
\hline $\begin{array}{l}\text { Valor do } \\
\text { índice }\end{array}$ & Características \\
\hline$\leq 5,9$ & Resfriamento muito elevado \\
\hline 6,0 a 8,9 & Resfriamento elevado \\
\hline 9,0 a 11,9 & Frio \\
\hline 12,0 a 14,9 & Desconforto ao frio \\
\hline 15,0 a 17,9 & Leve desconforto ao frio \\
\hline 18,0 a 20,9 & $\begin{array}{l}\text { Limite inferior da zona de } \\
\text { conforto }\end{array}$ \\
\hline 21,0 a 23,9 & Centro da zona de conforto \\
\hline 24,0 a 26,9 & $\begin{array}{l}\text { Limite superior da zona de } \\
\text { conforto }\end{array}$ \\
\hline $\begin{array}{l}27,0 \text { a } 29,9 \\
30,0 \text { a } 32,9 \\
\geq 33\end{array}$ & $\begin{array}{l}\text { Leve desconforto ao calor } \\
\text { Desconforto ao calor } \\
\text { Aquecimento elevado }\end{array}$ \\
\hline
\end{tabular}




\section{- Índice de temperatura efetiva com vento (TEv) - Missenard (1937)}

Elaborado pelo pesquisador francês Missenard em 1937 esta equação representa uma das metodologias utilizadas para mensurar o conforto térmico e a relação entre temperatura, umidade relativa e velocidade do vento.

Autores como Suping et. al. (1992, p. 65) utilizaram essa metodologia com o objetivo de testar a relação ente às condições do tempo e os efeitos fisiológicos no desempenho de atletas maratonistas na cidade de Beijing/China. De acordo com Suping et. al. (1992, p. 65) o índice de temperatura efetiva com vento pode ser expresso por:

$$
\mathrm{TEV}=37-\frac{37-t a}{0,68-0,0014 R H+\frac{1}{1,76+1,4 v^{0,75}}}-0,29 \mathrm{t}(1-\mathrm{RH} / 100)
$$

$$
\begin{gathered}
\text { ta = temperatura do ar } \\
\mathrm{RH}=\text { umidade relativa } \\
\mathrm{V}=\text { velocidade do vento }
\end{gathered}
$$

Fonte: Missenard (1937) apud Suping et. al. (1992, p.65).

\section{- Índice de Temperatura Efetiva/ Índice de temperatura Resultante (ITR) - Missernard (1948)}

Criado por Missernard em 1948, na França, este índice considera em sua equação os efeitos da umidade e do movimento do ar em indivíduos com ou sem vestuário (CARVALHO, 2006, p.69).

$\mathrm{Na}$ bibliografia consultada foram encontradas 2 denominações para a mesma equação, autor e ano: temperatura resultante (MONTEIRO, 2008, p.46) e Temperatura Efetiva (SUPING et. al., 1992, p. 65; CARVALHO, 2006. p.69)

Monteiro (2008, p.46) esclarece que a pesquisa de Missenard (1948) é semelhante àquelas realizadas por Houghten e Yaglou (1923) referente ao índice de temperatura efetiva, contudo, a diferença é que foi realizada com períodos de exposição de maior duração e baseada em experimentos de laboratório com pessoas em vários países.

$$
\begin{gathered}
\text { TR = Ts }-\mathbf{0 , 4}(\text { Ts }-\mathbf{1 0})(\mathbf{1}-\mathbf{U R} / \mathbf{1 0 0}) \\
\text { TR }=\text { temperatura resultante }\left({ }^{\circ} \mathrm{C}\right) \\
\text { Ts = temperatura do ar }\left(\text { bulbo seco }\left({ }^{\circ} \mathrm{C}\right)\right. \\
\text { UR }=\text { umidade relativa do ar }(\%)
\end{gathered}
$$

Fonte: Suping et. al. (1992, p. 65); Carvalho (2006, p.69).

Tanto para o Índice de temperatura efetiva com vento (TEv) quanto para o Índice de temperatura efetiva/ temperatura resultante foram utilizadas a classificação de conforto térmico elaborada por Fanger (1972) e reaplicada em 
pesquisas brasileiras (MAIA e GONÇALVES; 2002; GOBO, 2013; e NEDEL et. al., 2015).

Tabela 02 - Classes de conforto térmico aplicado aos índices de temperatura resultante (ITR) e índice de temperatura efetiva com vento (TEv).

\begin{tabular}{ccc}
\hline $\begin{array}{c}\text { Resultado dos } \\
\text { índices }\end{array}$ & Sensação térmica & Grau de estresse fisiológico \\
\hline$<13$ & Muito frio & Extremo estresse ao frio \\
$13-16$ & Frio & Tiritar \\
$16-19$ & Frio Moderado & Ligeiro resfriamento do corpo \\
$19-22$ & Ligeiramente frio & Vasoconstrição \\
$22-25$ & Confortável & Neutralidade térmica \\
$25-28$ & Ligeiramente quente & Ligeiro suor e vasodilatação \\
$28-31$ & Quente moderado & Suando \\
$31-34$ & Quente & Suor em profusão \\
$>34$ & Muito quente & Falha na termorregulação \\
\hline
\end{tabular}

Fonte: Adaptada de Fanger (1972), Maia e Gonçalves (2002, p.312), Gobo (2013, p. 80) e Nedel et. al. (2015, p.191).

\section{- Índice de temperatura equivalente percebida (TEP) - Monteiro (2008).}

$O$ índice de temperatura equivalente percebida (TEP) foi proposto pelo arquiteto brasileiro Monteiro (2008) em sua tese de doutorado. Este índice foi elaborado para condições externas na cidade de São Paulo e baseada em temperaturas equivalentes (MONTEIRO, 2008, p.204 e 205).

Os resultados desta equação representam o valor médio de percepção de sensação térmica de 1750 questionários aplicados com pessoas em pé e paradas, com vestimentas escolhidas por elas próprias.

Para sua proposição admitiu-se as seguintes condições para o ambiente de referência: temperatura radiante média igual a temperatura do ar $(\mathrm{Trm}=$ Tar); velocidade do ar aproximadamente igual a zero (var=0,1m/s); umidade relativa igual a cinquenta por cento ( $u r=50 \%)$.

\section{TEP $=-3,777+0,4828 * T_{a r}+0,5172 * T_{r m}+0,0802 * u r-$ \\ Var}

$$
\begin{gathered}
\text { TEP = temperatura equivalente percebida } \\
\mathrm{T}_{\mathrm{ar}}=\text { Temperatura do ar } \\
\mathrm{T}_{\mathrm{rm}}=\text { Temperatura radiante média } \\
\text { ur }=\text { umidade relativa do ar } \\
\mathrm{Var}=\text { velocidade do ar }
\end{gathered}
$$

Fonte: Monteiro (2008, p.205).

De acordo com Monteiro (2008, p. 206) as faixas interpretativas para a temperatura equivalente percebida (TEP) são: 
Tabela 3 - Faixas interpretativas para o índice de temperatura equivalente percebida.

\begin{tabular}{cc}
\hline$\underline{\text { TEP }}$ & Sensação \\
\hline$\frac{>50,0}{42,5 \sim 50,0}$ & $\frac{\text { Extremo calor }}{\text { Muito calor }}$ \\
$\frac{34,9 \sim 42,4}{27,3 \sim 34,8}$ & $\frac{\text { Calor }}{\text { Pouco calor }}$ \\
$\frac{25,4 \sim 27,2}{21,5 \sim 25,3}$ & $\frac{\text { Leve calor }}{\text { Neutralidade }}$ \\
$\frac{19,6 \sim 21,4}{12,0 \sim 19,5}$ & $\frac{\text { Leve frio }}{\text { Pouco frio }}$ \\
$\frac{4,4 \sim 11,9}{4,3 \sim-3,2}$ & Frio \\
$\frac{\text { Muito frio }}{\leq-3,2}$ & Extremo frio \\
\hline
\end{tabular}

- Diagrama de conforto térmico (INMET).

O diagrama de conforto humano, elaborado pelo Instituto Nacional de Meteorologia (INMET), é um dos poucos produtos voltados a análise do conforto térmico brasileiro. Para leitura deste diagrama é necessário o cruzamento de informações de temperatura do ar e umidade relativa. O local da abcissa indicará a situação de conforto térmico classificada em muito quente, muito seco, muito úmido, muito frio e confortável, sendo este último dividido em confortável, necessita de vento para o conforto e necessita de sol para o conforto (Figura 4).

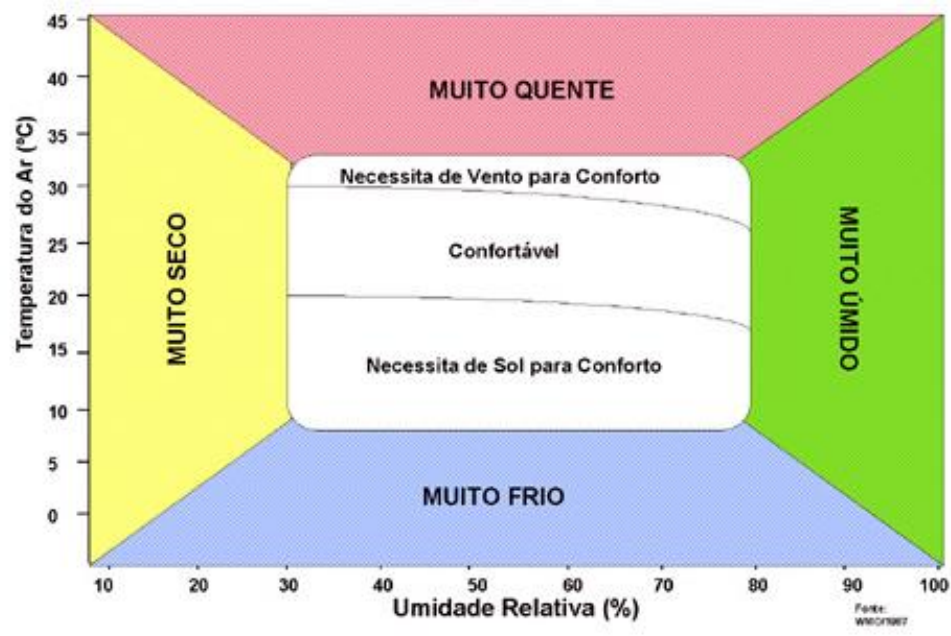

Figura 04 - Diagrama de conforto térmico - INMET (2006).Fonte: http://www.inmet.gov.br/portal/index.php?r=clima/confortotermicoHumano.

\section{- Predileção térmica da população residente em Presidente} Prudente (PT).

Esta análise foi elaborada a partir dos resultados do questionário aplicado pelos autores com a população residente na cidade de Presidente Prudente. Diferente das demais metodologias descritas esta considera apenas a predileção 
térmica da população entrevistada e, portanto, ainda que incipiente é uma primeira aproximação da pesquisa com os moradores da cidade estudada.

Este questionário foi obtido a partir das respostas de 300 moradores de diferentes bairros urbanos da cidade de Presidente Prudente, homens (121 entrevistados ou $40,3 \%$ do total) e mulheres (179 entrevistadas ou $59,6 \%$ do total), com idade superior a 15 anos (Figura 5).

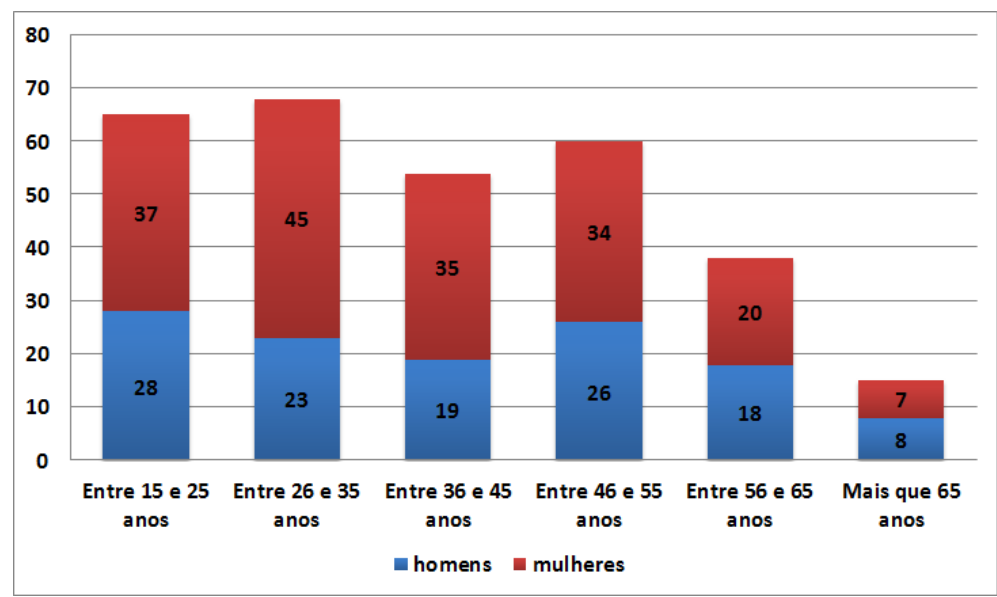

Figura 5 - Sexo e idade dos entrevistados.

Os dados foram obtidos em locais de circulação de pessoas, em atividade física leve ou nula (caminhando ou sentados). Os questionários foram aplicados em locais livres da exposição solar direta e com circulação de ar, como o centro da cidade, Universidade Estadual Paulista (UNESP) e postos de saúde. A escolha por diferentes locais para aplicação do questionário foi proposital. A intenção era abranger na pesquisa um grupo heterogêneo do ponto de vista social e econômico, além de atingir o maior número possível de moradores residentes nos diferentes bairros da cidade. Os resultados foram tabulados e analisados a partir do software de análise de questionários Sphinx.

Para obtenção dos dados referentes a predileção térmica a pesquisa foi embasada e adaptada de Fanger (1972). Na metodologia original as pessoas elegeram sensações térmicas confortáveis e desconfortáveis a partir de uma gradação entre o extremo quente e frio. No entanto, neste caso, foi realizada uma adaptação e os entrevistados indicaram valores absolutos das temperaturas em que se sentem confortáveis e desconfortáveis ao frio e calor. Durante a aplicação do questionário também foi informado aos entrevistados a temperatura do momento e a partir deste valor e de seu conhecimento prévio e subjetivo elegeram o valor em que começam a sentir frio e calor.

Para esta análise foram consideradas as respostas subjetivas referentes as questões: "a partir de qual temperatura você sente calor?"; "a partir de qual temperatura você sente frio?" e definiu-se a partir desses resultados os seguintes parâmetros e limiares de conforto, desconforto térmico ao calor e ao frio: 
Tabela 04 - Parâmetros definidos para a análise da predileção térmica dos residentes de Presidente Prudente a partir do questionário aplicado com a população.

\begin{tabular}{cccc}
\hline & $\begin{array}{c}\text { Homens e } \\
\text { mulheres }\end{array}$ & Mulheres & Homens \\
\hline $\begin{array}{c}\text { ao frio } \\
\text { Temperatura desconfortável }\end{array}$ & $17,4^{\circ} \mathrm{C}$ & $18,4^{\circ} \mathrm{C}$ & $16,4^{\circ} \mathrm{C}$ \\
Faixa de conforto térmico & $17,5^{\circ} \mathrm{C}-29,5^{\circ} \mathrm{C}$ & $18,5^{\circ} \mathrm{C}-$ & $16,5^{\circ} \mathrm{C}-$ \\
$29,4^{\circ} \mathrm{C}$ & $29,7^{\circ} \mathrm{C}$ \\
$\begin{array}{c}\text { Temperatura desconfortável } \\
\text { ao calor }\end{array}$ & $29,6^{\circ} \mathrm{C}$ & $29,5^{\circ} \mathrm{C}$ & $29,8^{\circ} \mathrm{C}$ \\
\hline
\end{tabular}

Fonte: Questionários aplicados na pesquisa.

\section{RESULTADOS E DISCUSSÃO}

Os resultados dos 6 testes de conforto térmico, de modo geral, apontaram resultados interessantes e diferentes de acordo com a metodologia empregada.

Os resultados obtidos a partir do Índice de temperatura e umidade (THI) - (THOM, 1959) demonstram que na maior parte dos dias analisados a população de Presidente Prudente encontra-se em condições agradáveis de conforto: limite inferior da zona de conforto, centro da zona de conforto, limite superior da zona de conforto (Figura 06).

Nesta equação são considerados apenas os dados de temperatura e umidade. Dentre as demais metodologias analisadas esta também é a que tem o maior número de classes de definições de conforto o que pode de certa forma detalhar excessivamente o resultado dificultando a compreensão real.

O período da manhã foi marcadamente representado por resultados entre 18 e 20,9, denominado por "limite inferior da zona de conforto" e aproximadamente $35,5 \%$ das manhãs tiveram essa caracterização. No período da tarde, 42,3\% dos dias analisados, ou 1856 dias, foram considerados por esta metodologia dentro do "limite superior da zona de conforto". No período da noite, na maioria dos dias, esta situação também se repetiu. Obteve-se 39,7\% das noites classificadas como dentro do "limite superior da zona de conforto" e 38,4\% como no "centro da zona de conforto".

Fato interessante para esta análise nos últimos 11 anos não ocorreram em nenhum período analisado situações consideradas como "desconfortável ao calor" e "aquecimento elevado", as classes mais desconfortáveis ao calor em Presidente Prudente.

Situações consideradas com extremas frias também não foram expressivas e apenas constatadas no período da manhã. Contabilizou-se 6 manhãs com "resfriamento muito elevado", 0,1\% da série; e, 35 manhãs como "resfriamento elevado", aproximadamente $0,8 \%$ da série. 


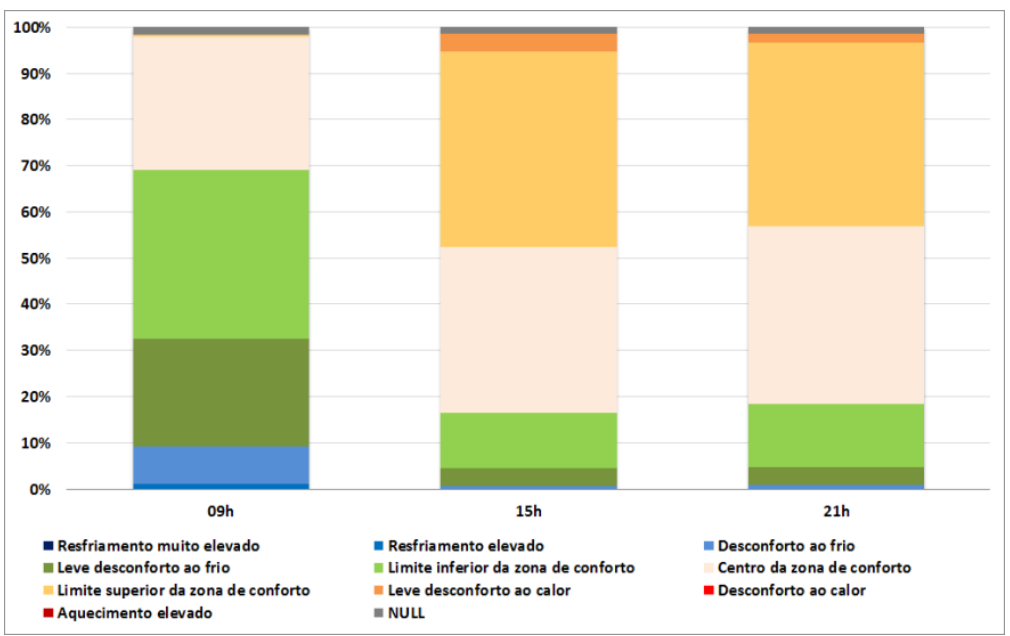

Figura 06 - Gráfico referente as condições de conforto térmico para as 9h, 15h, e $21 \mathrm{~h}$ (2005- 2016) partir do Índice de temperatura e umidade (THOM, 1959)

Dentre os demais índices testados o índice de temperatura efetiva com vento (TEv) de Missenard (1937) foi o que apresentou o maior número de dias considerados desconfortáveis ao frio classificados em: muito frio, frio, frio moderado (Figura 07). Observa-se, para este índice, uma tendência ao resfriamento que muitas vezes não são condizentes com a situação do conforto térmico real.

Especialmente durante as manhãs a predominância foi de $50,2 \%$ de dias "muito frio"; $27,0 \%$ de dias "frios"; e 19,2\% com "frio moderado". Ainda para o período da manhã não foram contabilizados situações de desconforto ao calor, em todas as classes, e apenas um único dia foi classificado como confortável.

Nos períodos da tarde e da noite prevaleceram as ocorrências de dias "confortáveis": $25,7 \%$ e 22,6\% respectivamente. Nestes períodos também foram verificadas situações desconfortáveis ao calor. Ainda que em menor frequência em relação as classes desconfortáveis ao frio, as classes ligeiramente quente e quente moderado representaram $14,2 \%$ e 3,3\% das tardes e $12,2 \%$ e $1,4 \%$ das noites.

Durante os 11 anos analisados apenas 1 tarde e 1 noite foram classificados como quentes e em nenhum dia verificou-se a classe "muito quente" o extremo mais desconfortável ao calor desta metodologia.

Em sua pesquisa Gobo (2013, p.40) também observou essa mesma limitação metodológica para o índice de temperatura efetiva com vento. Segundo 0 autor os melhores resultados foram gerados quando há predominância de vento, pois, em situações contrárias, este índice tende a maximizar o resfriamento pelo vento, gerando um erro no resultado real do conforto térmico observado. Este foi um dos motivos que o levou a utilizar este índice apenas para os meses representativos de outono e inverno, quando há predominância de vento em todas as regiões do estado do Rio Grande do Sul/ Brasil. 


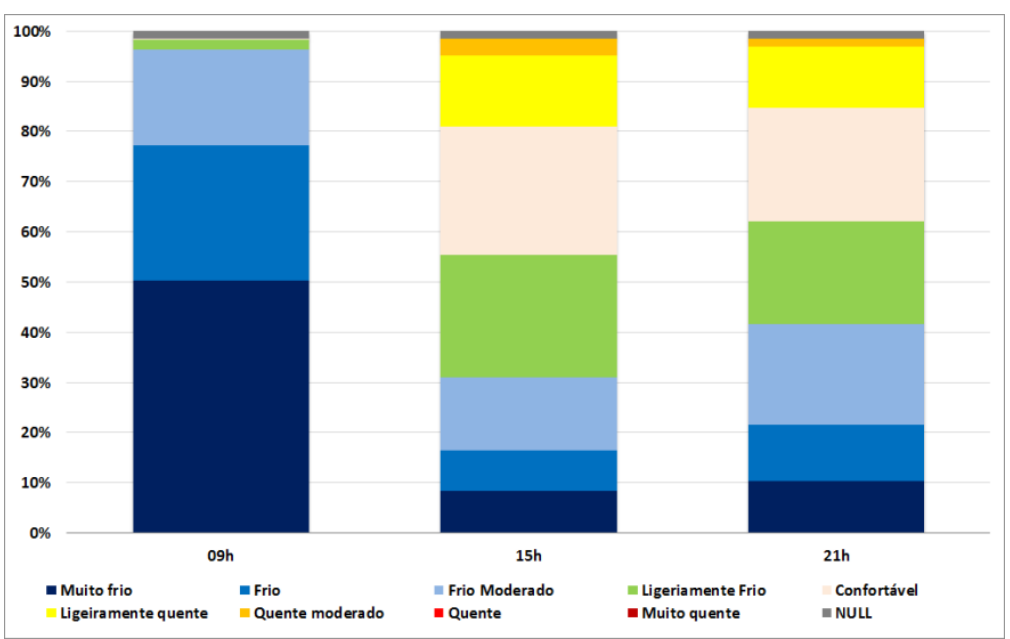

Figura 07 - Gráfico referente as condições de conforto térmico para as $9 \mathrm{~h}, 15 \mathrm{~h}$, e $21 \mathrm{~h}$ (2005- 2016) partir do Índice de temperatura efetiva com vento (MISSENARD, 1937).

O índice de temperatura efetiva/ resultante de Missenard (1948), apesar de considerar em sua equação apenas os dados de temperatura e umidade apresentou resultados mais fidedignos as situações reais em Presidente Prudente, quando comparado ao índice anterior. A grande diferença entre as duas técnicas é que o índice de temperatura efetiva não classificou uma quantia de dias significativos relacionados aos extremos frios, como a classe "muito frio", por exemplo (Figura 08).

Diferente da técnica anterior foi contabilizado uma frequência maior de manhãs confortáveis, $10,9 \%$, mas também foi observada uma predominância significativa de manhãs "ligeiramente frias", 38\%; "frio moderado", 30,2\%; "frio", 13,2\% e "muito frio" em 6,1\%, que juntas contabilizam 87,5\% das ocorrências.

Nos períodos da tarde e noite os resultados foram muito parecidos. De modo geral ocorreu um domínio de situações confortáveis (39,8\% e 38,4\% para a tarde e noite) e ligeiramente quente (30,4\% e $27,9 \%$ ). Assim como no índice anterior não foram constatados muitos dias com extremo desconforto ao calor. Apenas 56 tardes e 26 noites tiveram os resultados de "quente moderado" e em nenhum período (manhã, tarde e noite) verificou-se situações "quente" e "muito quente". 


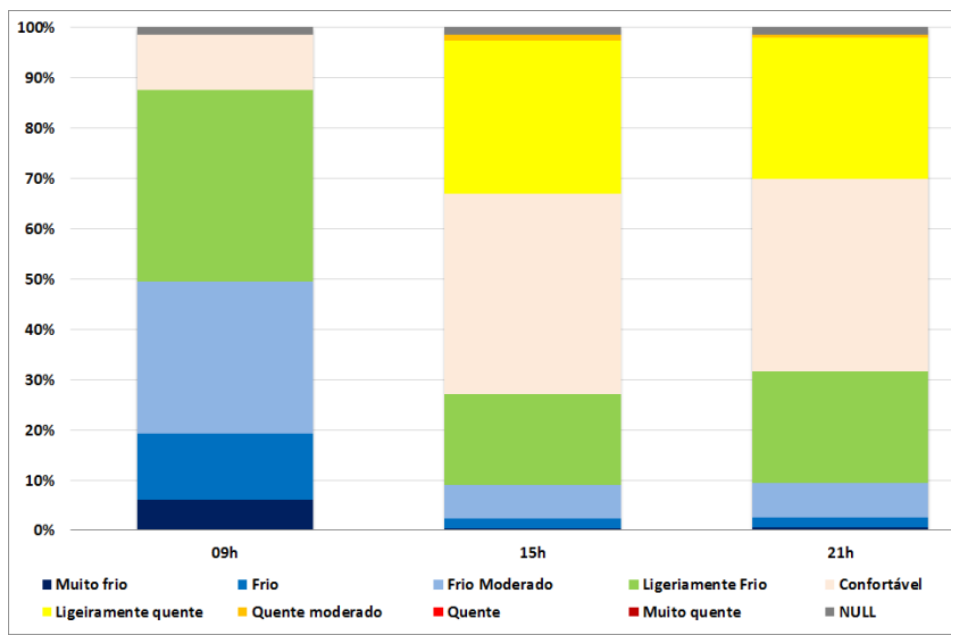

Figura 08 - Gráfico referente as condições de conforto térmico para as $9 \mathrm{~h}, 15 \mathrm{~h}$, e $21 \mathrm{~h}$ (2005-2016) partir do Índice de temperatura efetiva (MISSENARD, 1948).

O índice de temperatura equivalente percebida (TEP) foi uma das poucas metodologias pensadas exclusivamente para o contexto brasileiro e em especial para a cidade de São Paulo.

A vantagem desta técnica é que ela considera em sua equação os dados de temperatura, umidade e ventos e por esta característica também pode ser definida como uma das mais completas por considerar uma gama maior de variáveis atmosféricas (umidade, temperatura e ventos). A desvantagem nesta metodologia está no número elevado de classes, 11, que podem de certa forma mascarar e/ou confundirem a leitura dos resultados.

Para esta técnica observa-se que há uma predominância de classes neutras/confortáveis e também de classes próximas: "leve calor" e "leve frio", "pouco calor" e "pouco frio" e "frio" (Figura 09).

Os extremos de calor e frio não foram constatados para esta análise.

No período da manhã a maioria dos dias foi "pouco frio" (43,6\%), seguido pela classe de "neutralidade" (23\%); à tarde predominaram as situações "neutras" (37,5\%) e "leve calor" com 17,6\% dos dias; no período noturno a maior incidência também foi de "neutralidade", 36,2\%, e "pouco calor", 18,9\%. 


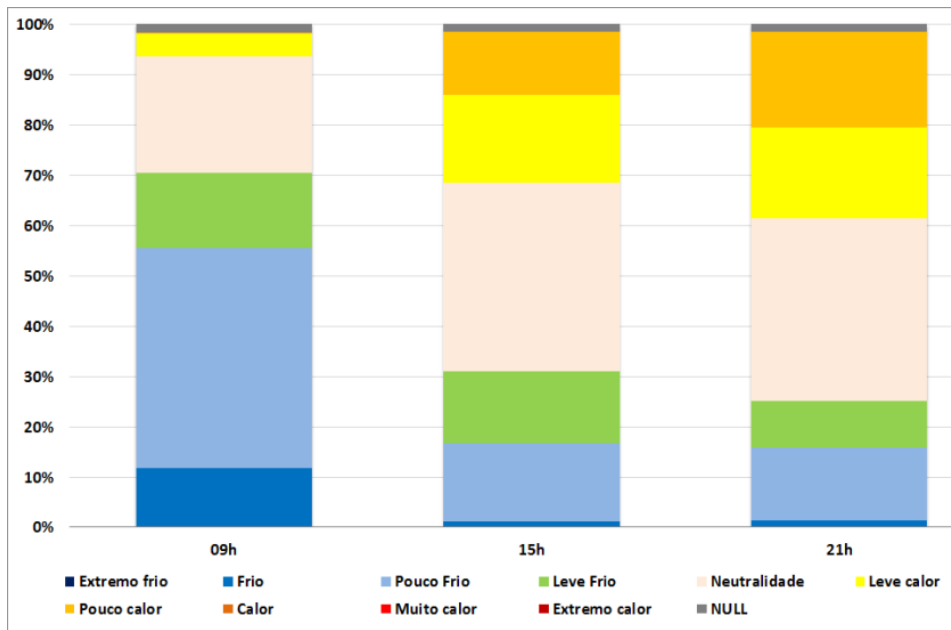

Figura 09 - Gráfico referente as condições de conforto térmico para as $9 \mathrm{~h}, 15 \mathrm{~h}$, e $21 \mathrm{~h}$ (2005- 2016) partir do Índice de temperatura equivalente percebida (MONTEIRO, 2008).

O diagrama de conforto térmico (INMET) foi uma metodologia diferente dos tradicionais índices empregada nesta pesquisa (Figura 10).

Em sua aplicação esta metodologia utiliza os dados de temperatura e umidade e apresentam de forma clara uma faixa considerada "confortável". Contudo para a identificação de episódios extremos e desconfortáveis esta não é uma metodologia muito eficaz. Os maiores problemas ocorrem quando se tem dados de umidade superiores a $80 \%$ e inferiores a $30 \%$.

Para elucidar este problema supõe-se uma situação hipotética em que dois dados apresentam temperaturas completamente diferentes: $5^{\circ} \mathrm{C}$ e $30^{\circ} \mathrm{C}$, mas ambos com umidade superior a 90\%. De acordo com o diagrama estas duas situações serão classificadas da mesma forma: "muito úmido". O mesmo ocorre com os dados com umidade inferiores a $30 \%$, onde são classificados como "muito seco".

Entende-se que o diagrama classifica, neste caso, o resultado a partir da variável mais expressiva, mas que nem sempre essa classificação é adequada e recomendada para análises de conforto térmico, ou passível de utilização com o objetivo de comparar um conjunto de dados.

Observa-se, portanto, que esta metodologia é limitada apenas para a identificação de situações confortáveis, onde as variáveis temperatura e umidade possuem um maior detalhamento no diagrama (área central do diagrama) sendo, inclusive, subdivididas em outras 2 categorias: "necessita de vento para conforto", "necessita de sol para conforto".

De acordo com esta metodologia a série histórica de 2005 a 2016 pode ser classificada principalmente como "muito úmida" no horário das $9 \mathrm{~h}$, com aproximadamente $50,9 \%$ dos dias, e "confortável" para o período da tarde (66\% dos dias) e da noite (56,9\% dos dias analisados).

As classes mais extremas: muito quente e muito frio, foram as que tiveram o menor número de dias com as referidas classificações. Para a classificação "Muito quente" observou-se 209 ocorrências divididos nos horários 
das $15 \mathrm{~h}$ (109) e $21 \mathrm{~h}$ (100). A classe "muito fria", por sua vez, foi contabilizada apenas em 19 dias, durante toda a série, e apenas no período da manhã.

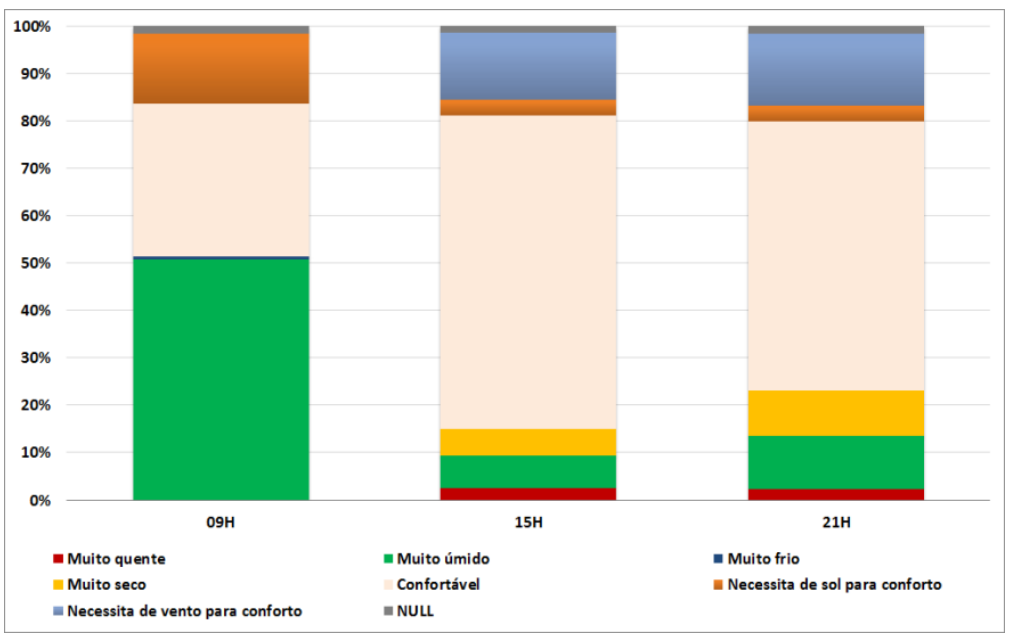

Figura 10 - Gráfico referente as condições de conforto térmico para as $9 \mathrm{~h}, 15 \mathrm{~h}$, e $21 \mathrm{~h}$ (2005- 2016) partir do Diagrama de conforto térmico (INMET).

Por fim a última metodologia analisada foram as respostas de predileção dos habitantes de Presidente Prudente e considera apenas os valores de temperatura.

De acordo com os resultados do questionário a população, homens e mulheres, tiveram em média $74,2 \%$ das manhãs com situações de conforto térmico e $73,9 \%$ das tardes também consideradas agradáveis. O horário com menos situações confortáveis, dentre os demais, foi o das $21 \mathrm{~h}$ com $70,8 \%$, um valor elevado comparado aos demais índices (Figura 11).

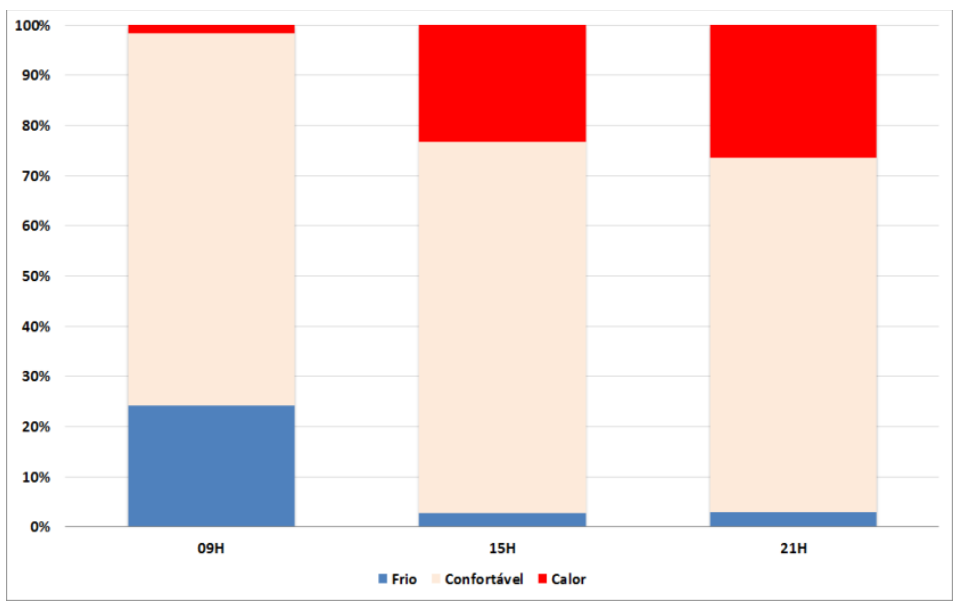

Figura 11 - Gráfico referente as condições de conforto térmico para homens e mulheres as $9 \mathrm{~h}, 15 \mathrm{~h}$, e $21 \mathrm{~h}$ (2005-2016) partir do resultado do questionário de predileção térmica (PT) para a cidade de Presidente Prudente. 


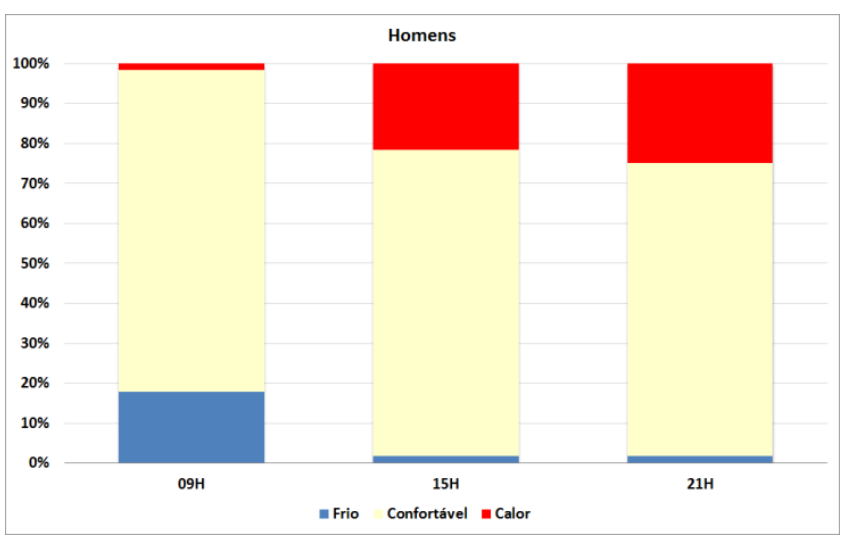

Figura 12 - Gráfico referente as condições de conforto térmico para homens as $9 \mathrm{~h}, 15 \mathrm{~h}$, e 21h (2005- 2016) partir do resultado do questionário de predileção térmica (PT) para a cidade de Presidente Prudente.

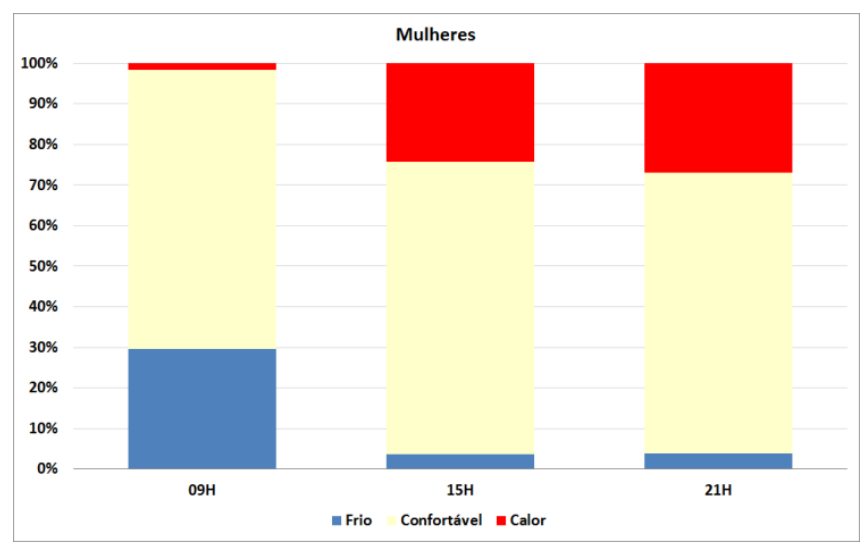

Figura 13 - Gráfico referente as condições de conforto térmico para mulheres as $9 \mathrm{~h}$, 15h, e $21 \mathrm{~h}$ (2005- 2016) partir do resultado do questionário de predileção térmica (PT) para a cidade de Presidente Prudente.

Dentre os testes analisados este foi o que apresentou o maior número de dias com situações consideradas "confortáveis", nos três horários analisados, principalmente por considerar uma grande amplitude na faixa de conforto, $12^{\circ} \mathrm{C}$.

Em relação às diferenças de respostas obtidas entre homens e mulheres observou pouca diferença para os limiares de temperatura desconfortáveis ao calor, mas a diferença de $1,7^{\circ} \mathrm{C}$ para as temperaturas desconfortáveis ao frio representou uma importante diferença em relação ao número de dias desagradáveis entre os dois sexos.

De acordo com esta análise as mulheres sentem, em relação aos homens, mais que o dobro do número de dias desconfortáveis ao frio, principalmente durante as noites com uma diferença de 118,2\% (168 dias desconfortáveis ao frio para as mulheres e 77 dias para os homens); seguido pelo horário das $15 \mathrm{~h}$ com 93,8\% (157 dias com situações desconfortáveis ao frio para as mulheres e 81 para homens) e das 9h, com 65,6\% (1298 dias com temperaturas desconfortáveis para as mulheres e 784 para os homens). 
Tal resultado condiz com o resultado de outras pesquisas sobre 0 conforto térmico como a Burse (1979) e LeBlanc et. al. (1978) e pode ser explicado pelas próprias condições fisiológicas e estrutura corporal diferente entre homens e mulheres. Burse (1979, p.687) explica que durante situações de frio as mulheres tem geralmente:

\begin{abstract}
less capability for maximum heat production by either exercise or shivering, a more extensively vasoconstricted periphery, lower foot, hand, and mean skin temperatures, greater surface heat losses, especially from the geometrically thinner extremities, increased rates of extremity, but not core, cooling, and relatively greater risk of cold injury.
\end{abstract}

Nesta análise também ficou evidente o baixo número de dias com temperaturas desconfortáveis ao calor no horário das $9 \mathrm{~h}$ da manhã e observado principalmente nos horários das $15 \mathrm{~h}$ e $21 \mathrm{~h}$, com 23,3\% e 26,4\% dos dias avaliados desconfortáveis ao calor respectivamente.

Tal resultado nos leva a pensar sobre os motivos intrínsecos nestas respostas e pensar em hipóteses que podem ser explicadas pela adaptação humana em relação aos ambientes em que habitam ou mesmo uma limitação metodológica. É possível que os habitantes desta cidade realmente estejam acostumados com altas temperaturas e, portanto, criaram mecanismos de adaptação a tais condições devido a sua frequência e permanência ao longo de quase todo o ano. Este argumento também é confirmado pela eleição de temperaturas consideradas elevadas pela bibliografia em biometeorologia humana (acima de $25^{\circ} \mathrm{C}$, por exemplo) indicando que os habitantes se sentem melhores e preferem temperaturas mais quentes e estão pouco adaptados a situações de frio;

Os outros dois fatores limitantes deste questionário recaem sobre a opção metodológica:

- Foram considerados pelo questionário apenas informações referentes à temperatura e desconsiderado propositalmente informações sobre umidade e ventos. Sabe-se que o conforto térmico humano está atrelado a estes e outros elementos do clima, contudo, observou-se uma dificuldade para encontrar pessoas que tenham conhecimento aprofundado sobre estes elementos. Normalmente as pessoas desconhecem o papel da umidade e dos ventos, mas identificam dias frios ou quentes a partir das informações que obtém cotidianamente, pela percepção ou senso comum, principalmente sobre as temperaturas: "hoje o dia está quente", "hoje o dia está frio". Trata-se, portanto, de uma análise simples, sem grande rigor matemático, e sem considerar equações e outros elementos do clima, mas importante no sentido de possibilitar que os principais sujeitos desta pesquisa sejam ouvidos.

- O terceiro e último argumento que pode ser contrário a esta metodologia refere-se ao desconhecimento das pessoas em definir um valor exato aos quais se sentem desconfortáveis ao frio e ao calor. De fato, as pessoas podem não saber exatamente as temperaturas em que se sentem desconfortáveis uma vez que como visto na bibliografia o conforto térmico é dependente de inúmeras variáveis físicas, biológicas e subjetivas individuais e coletivas que compõem essa situação, mas também se deve considerar que esta análise é resultado do voto médio. 
Foram analisadas as respostas de 300 pessoas, homens e mulheres, de diferentes faixas etárias e perfis socioeconômicos e experiências que juntas compuseram o resultado aqui apresentado. Além disso, no momento da pesquisa, também foi informado à população a temperatura momentânea. Mesmo que as pessoas não tivessem um conhecimento aprimorado sobre os valores de temperatura elas puderam parametrizar suas respostas a partir da sensação no momento da pesquisa.

Por fim buscou-se comparar os resultados obtidos pelas diferentes técnicas. Como as faixas de classificação são diferentes a opção foi comparar o que todas as técnicas têm em comum: os limiares de conforto. Nas figuras 14, 15 e 16 é possível verificar o número de dias confortáveis de acordo com as diferentes metodologias empregadas para os horários das 9h, 15h e 21 horas.

Neste gráfico são apresentados apenas os resultados do "centro da zona de conforto" do Índice de Temperatura e Umidade (THI) - (THOM, 1959), "confortável" do índice de temperatura efetiva com vento (MISSENARD, 1937), "confortável" do índice de temperatura efetiva (MISSENARD, 1948),"neutralidade" do índice de temperatura equivalente percebida (TEP) (MONTEIRO, 2008), "confortável" do diagrama de conforto térmico (INMET), e "faixa de conforto térmico", resultado do questionário aplicado à população de Presidente Prudente.

Os resultados apontam que as técnicas do Diagrama de conforto térmico e as Respostas da predileção térmica foram aqueles em que mais se constatou situações confortáveis especialmente nos horários $15 \mathrm{~h}$ e $21 \mathrm{~h}$, contudo, não se podem esquecer algumas limitações apresentadas por essas metodologias, descritas acima.

Para as demais técnicas observa-se que tiveram a frequência de dias confortáveis parecidas especialmente nos períodos da tarde e noite. Para essas quatro técnicas a porcentagem de tardes confortáveis ficou entre 30,9\%, com o índice de temperatura efetiva com vento, e 39,8\% com o índice de temperatura efetiva; no período da noite os resultados foram ainda mais próximos e ficaram entre 35,4\% (índice de temperatura efetiva com vento) a 38,4\% (índice de temperatura efetiva e índice de temperatura e umidade).

As maiores diferenças na frequência de dias confortáveis, entre as técnicas, ocorreram no período da manhã e este também foi o período do dia com o menor número de situações confortáveis. Algumas técnicas, como a do índice de temperatura efetiva com vento, apresentaram um valor muito baixo de situações confortáveis pela manhã e não ultrapassou $5,9 \%$ dos casos. As demais ficaram entre 10,9\% (Índice de temperatura efetiva) e 28,2\% (Índice de temperatura e umidade). Este resultado é interessante para a análise comparativa entre os índices porque demonstra certa similaridade entre técnicas empregadas quando há um predomínio de temperaturas mais elevadas (período da tarde e noite), mas a grande diferença ocorre no período da manhã quando as temperaturas estão mais amenas e a umidade mais elevada. Também se devem considerar as classes de conforto empregadas. Alguns índices, com mais níveis classificatórios, acabam por confundir e decompõem os resultados dificultando a comparação. 

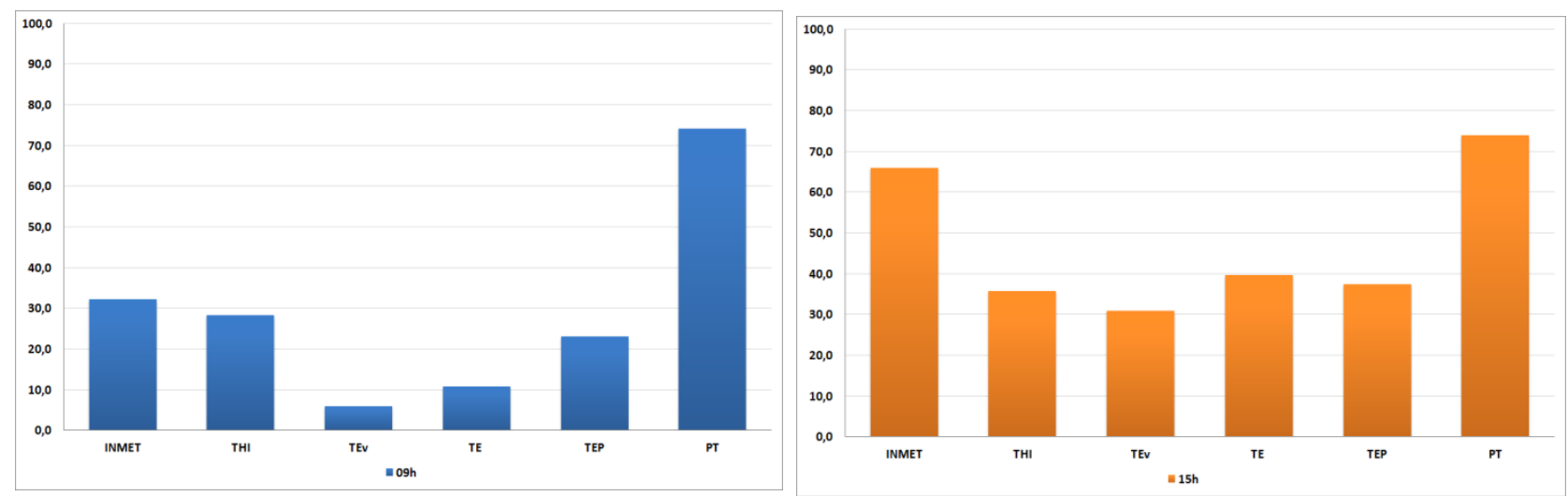

Figura 14 e 15 - Porcentagem de dias confortáveis, de acordo com as diferentes metodologias empregadas, nos horários das $9 \mathrm{~h}$ e $15 \mathrm{~h}$.

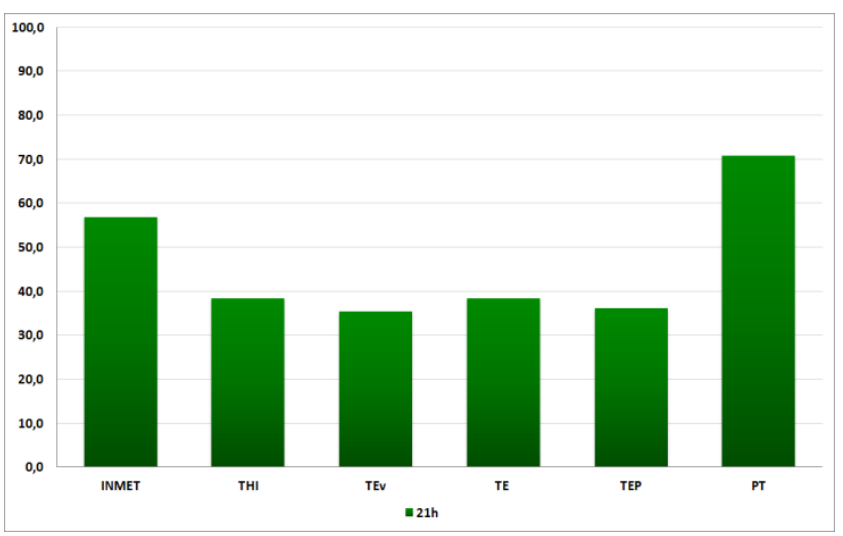

Figura 16 - Porcentagem de dias confortáveis, de acordo com as diferentes metodologias empregadas, nos horários das $21 \mathrm{~h}$.

\section{CONCLUSÕES}

Nesta pesquisa foram analisados e comparados 6 metodologias para análise do conforto térmico humano. Os resultados apresentaram diferenças importantes na forma em que avaliam o conforto térmico que está atrelado aos dados utilizados e os métodos de classificação.

Em específico aos índices de temperatura e umidade (THI), temperatura efetiva com vento (TEv), temperatura efetiva, índice de temperatura equivalente percebida, diagrama de conforto térmico e o questionário de predileção térmica, utilizados nesta pesquisa, os resultados mostraram-se diferentes entre as técnicas, mas que também confirmam o pouco consenso entre as metodologias utilizadas atualmente em análise bioclimáticas, e definidas, muito mais, pelo objetivo de cada pesquisa.

O índice de Temperatura e umidade (THI) foi um dos utilizados em que mais classificou o conforto térmico em Presidente Prudente como agradáveis. Para esta metodologia existe um grande número de classes que ao mesmo tempo em que detalha também dificulta a compreensão real. O maior número 
das manhãs foi classificado com situações dentro do "limite inferior da zona de conforto" e os horários da tarde e noite em situações de "limite superior da zona de conforto".

O índice de temperatura efetiva com vento (TEv) foi um dos índices em que apresentou a maior quantidade de dias desconfortáveis ao frio dentre as demais. Foram constatados por esta técnica inclusive situações consideradas de extremo frio (muito frio), fato este inexistente para as demais metodologias. A partir desta equação verifica-se uma tendência em subestimar as condições atmosféricas para situações desconfortáveis ao frio.

$O$ índice de temperatura efetiva, proposto pelo mesmo pesquisador francês da técnica supracitada, parece ter corrigido na versão mais recente (1948) os problemas metodológicos do índice de temperatura efetiva com vento (TEv)- (MISSENARD, 1937). Ainda que seja mais simplória, por considerar apenas os dados de temperatura e umidade, de acordo com esta análise, não se obteve muitos dias classificados com frio extremo, característica esta condizente com as situações reais da cidade estudada. Para esta metodologia a maior parte das manhãs foram ligeiramente frias e no período da tarde e noite, confortáveis.

$O$ índice de temperatura equivalente percebida (TEP), juntamente com o Diagrama de conforto térmico foram algumas das poucas metodologias pensadas e originadas em nível nacional. O Índice de temperatura equivalente percebida (TEP) mostrou-se eficaz para este tipo de análise sem subestimar ou superestimar situações de conforto. Para esta análise os resultados da equação indicaram uma predominância de classes neutras/confortáveis e outras próximas.

O diagrama de conforto térmico definiu a maior parte das manhãs como "muito úmido" enquanto que os períodos da tarde e noite foram classificados como "confortável". Para esta metodologia verifica-se que há problemas com valores extremos de umidade que podem ser classificados na mesma categoria, por exemplo, "muito úmidos", mas que de fato não representam as condições térmicas, importantes para análises de conforto térmico.

Por fim a última técnica obtida a partir do questionário de predileção térmica foi uma tentativa de aproximar o voto da população nas análises de conforto térmico. Para esta análise $74,2 \%$ das manhãs, $73,9 \%$ das tardes e $70,8 \%$ das noites, foram consideradas agradáveis. Esta metodologia apresenta limitações uma vez que considera apenas os votos médios de temperatura, além dos problemas intrínsecos à análises quali-subjetivas. Contudo também apresentou uma distinção importante para discussão do conforto térmico e as diferenças biológicas de sexo, principalmente, neste caso, referentes os desconforto ao frio, muito mais efetivo e intolerante para as mulheres, com aproximadamente mais que o dobro de situações desconfortáveis quando comparadas aos homens.

\section{AGRADECIMENTOS}

Os autores agradecem ao amigo Vinicius Carmello pelas contribuições e leitura atenta do artigo e abstract; ao prof. Tadeu Tommaselli pela disponibilização dos dados; e também ao Campus France, Bourse Eiffel, pelo financiamento em nível de doutorado. 


\section{REFERÊNCIAS BIBLIOGRÁFICAS}

BESANCENOT, J. P. Climat et Santé. $1^{a}$ edition. Paris/França: Dépôt legal, : 2001, 127p.

BOGO, A.; PIETROBON, C. E.; BARBOSA, M. J.; GOULART, S.; PITTA, T.; LAMBERTS, R. Bioclimatologia aplicada ao projeto de edificações visando o conforto térmico. Núcleo de pesquisas em construção. Departamento de engenharia civil. Universidade Federalde Santa Catarina. Relatório Interno 02/94. $183 \mathrm{p}$.

BOUBAKER, H. B. Les paroxysmes climato-thermiques em Tunisie: approche méthodologique et etude de cas. Climatologie. Revue de l'association Internationale de climatologie, Grenoble, volume 7, p. $57-87,2010$.

BURSE, R. L.; Sex differences in human thermoregulatory response to heat and cold stress, Hum. Factors, 21, 687- 699. 1979.

CARDOSO, R. S. Classificação de potenciais unidades climáticas em Presidente Prudente-SP. 2015. 137f. Dissertação (Mestrado em Geografia) - Universidade Estadual Paulista, Presidente Prudente/SP.

CARVALHO, V. F. M.a de. Contributos bioclimáticos para o planejamento urbano sustentável: medidas de mitigação e de adaptação enquanto resposta às alterações climáticas. 2006. 336 f. Dissertação (Mestrado em planejamento e projecto do ambiente urbano). Faculdade de engenharia da Universidade do Porto/Portugal.

COLLINS, K. J.; EXTON-SMITH, A. N.; DORÉ, C. Urban Hypothermia: preferred temperature and thermal perception in old age. British Medical Journal, v. 282, p. 175-177, jan. 1981.

Diagrama de conforto térmico - INMET (2006). Disponível em: <http://www.inmet.gov.br/portal/index.php?r=clima/confortotermicoHumano>. Acessado em: 09/05/2017.

DUBREUIL, V. ; FANTE, K. P. ; PLANCHON, O. ; SANT'ANNA NETO, J. L. Les types de climats annuels au Brésil : une application de la classification de Köppen de 1961 à 2015. EchoGéo [Online], 41, 2017, 22 p. Disponível em : < http://echogeo.revues.org/15017> Acessado em : 30/09/2017.

ESCOURROU, G. Le climat et la ville. 1a edição. Luçon: Éditions Nathan, 1991. $190 \mathrm{p}$.

FANGER, P. O. Thermal comfort, analysus and application in environmental engineering. New York: McGraw Hill, 1972.

FANTE, K. P. Variabilidade da temperatura em áreas urbanas não metropolitanas do estado de São Paulo - Brasil no período de 1961 a 2011. 2014. 254 f. Dissertação (Mestrado em Geografia). Faculdade de Ciência e Tecnologia da Universidade estadual Paulista UNESP, Presidente Prudente/SP.

FROTA, A. B. SCHIFFER, S. R. Manual do conforto térmico. 5a edição. São Paulo: Studio Nobel. 2001, 244 p. $1^{\text {a }}$ edição 1987, Livraria Nobel S.A.

FUNARI, F. L. O Índice de Sensação Térmica Humana em função dos tipos de tempo na Região Metropolitana de São Paulo. 2006. 108 f. Tese de Doutorado. 
Faculdade de Filosofia, Letras e Ciências Humanas da Universidade de São Paulo, São Paulo.

GARCÍA, F. F. Manual de climatologia aplicada: clima, medio ambiente y planificación. Primeira reimpresión. Madrid/ Espanha: Editorial Sintesis, noviembre 1996.

GOBO, J. P. A. Regionalização climática do Rio Grande do Sul com base no zoneamento do conforto térmico humano. 2013, 184 p. Dissertação (mestrado). Faculdade de Filosofia, Letras e Ciências Humanas da Universidade de São Paulo, São Paulo.

GOBO, J. P. A.; BORGES, D.C.; BARATTO, J.; SILVEIRA, T. S.; ONÇA, D. S.; FARIA, M. R. GALVANI, E. Avaliação da percepção climática de homens e mulheres e do conforto térmico em Santa Maria/RS. Boletim Paulista de Geografia, 2017, v. 96, p.31-50.

GÓMEZ, A. L.; GARCÍA, F. F.; ARROYO, F.; MARTÍN-VIDE, J.; CUADRAT, J. Ma. El clima de las ciudades españolas. Madrid/Espanha: Ediciones Cátedra, S.A., 1993. $268 \mathrm{p}$.

JENDRITZKY, G. Human biometeorology part I. Experientia. 499, p.733-740, 1993.

KRÜGER, E. L.; DRACH, P. R. C.; EMMANUEL, R.; CORBELLA, O. D. Estudo de conforto térmico em região de clima temperado: o caso de Glasgow, Reino Unido. Ambiente Construído: Porto Alegre, v. 12, n.1, p 7 - 25, jan/mar 2012.

LEBLANC, J.; CÔTÉ, J.; DULAC, S; DULONG-TURCOT, F. Effects of age, sex, and physical fitness on responses to local cooling. J appl Physiol Respor Environ Exerc Physiol, 1978. May; 44(5): 813-7. Disponível em: <https://www.ncbi.nlm.nih.gov/pubmed/649481?dopt=Abstract> Acessado em $18 / 11 / 2017$.

MAIA, J.A.; GONÇALVES, F. L. T. Uma análise do conforto térmico e suas relações meteorotrópicas na cidade de São Paulo - parte 1. In: XII CONGRESSO BRASILEIRO DE METEOROLOGIA, 2002, Foz do Iguaçu. Anais...2002, p.305314.

MISSENARD. L'Homme et le climat. Paris. 1937.

MISSENARD, H. Equivalence thermique dês ambience. Chaleur et industrie, 4. p.159-183. 1948.

MONTEIRO, L. M. Modelos preditivos de conforto térmico: quantificação de relações entre variáveis microclimáticas e de sensação térmica para avaliação e projeto de espaços abertos. 2008. 378 f. Tese (Doutorado em tecnologia da arquitetura/Faculdade de Arquitetura e urbanismo da Universidade de São Paulo FAU/USP), São Paulo/SP.

MONTEIRO, A. Riscos climáticos: hazards, áleas, episódios extremos. In: AMORIM, M. C. de C. T; SANT'ANNA NETO, J. L; MONTEIRO, A. Climatologia urbana e regional. Questões teórias e estudos de caso. $1^{a}$ edição. São Paulo: Outras expressões, 2013, p.143 - 171.

NEDEL, A. S.; GONÇALVES, F. L. T.; MACEDO JÚNIOR, C.; CARDOSO, M.R.A. Climatology of the human thermal comfort on São Paulo metropolitan area: indoors and outdoors. Revista brasileira de geofísica, 33(2), p.185 - 204, 2015. 
NIKOLOPOULOU, M., STEEMERS, K. Thermal comfort and psychological adaptation as a guide for designing urban spaces. Energy and Buildings, 35, p. 95 - 101, 2003.

PEREIRA, A. R. F; ALEIXO, N. C. R.; SILVA NETO, J. C. A. Abordagem introdutória sobre o conforto térmico em moradias da cidade de Tefé-AM. In: XII SBCG SIMPÓSIO BRASILEIRO DE CLIMATOLOGIA GEOGRÁFICA， 2016, Goiânia/GO. Anais...2016, p. 918 - 929.

SANT'ANNA NETO, J. L.; TOMMASELLI, J. T. G. O tempo e o clima de Presidente Prudente. $1^{a}$ edição. Presidente Prudente:Copyright, 2009, 72 p.

SIPLE, P. A., PASSEL, C. F. Measurements of dry atmospheric cooling in subfreezing temperatures. Proc. Amer. Philos. Soc., 89, p.177-199, 1945

SUPING, G.; GUANGLIN, M.; YANWEN, W.; JI, L. Study of the relationships between weather conditions and the marathon race and of meteorotropic effects on distance runners. International Journal of Biometeorology, 36, p.63-68, 1992.

THOM, E.C. Disconfort index Londres: Weatherwise. p. 57 - 61, 1959 